\title{
Individual risk profiling for breast cancer recurrence: towards tailored follow-up schemes
}

\author{
J Kraeima ${ }^{1,2}$, S Siesling ${ }^{1,3}$, I M H Vliegen ${ }^{2}$, J M Klaase ${ }^{4}$ and M J IJzerman ${ }^{\star, 1}$ \\ ${ }^{1}$ Department of Health Technology and Service Research (HTSR), MIRA institute for Biomedical Technology and Technical \\ Medicine, University of Twente, PO Box 217, Enschede 7500 AE, The Netherlands; ${ }^{2}$ Centre for Healthcare Operations \\ Improvement and Research (CHOIR), Centre for Telematics and Information Technology (CTIT), PO Box 217, Enschede 7500 AE, \\ The Netherlands; ${ }^{3}$ Department of Registration and Research, Comprehensive Cancer Centre The Netherlands (IKNL), PO Box \\ 19079, Utrecht 3511 GD, The Netherlands and ${ }^{4}$ Department of Surgery, Medical Spectrum of Twente, PO Box 50000, Enschede \\ 7500 KA, The Netherlands
}

Background: Breast cancer follow-up is not tailored to the risk of locoregional recurrences (LRRs) in individual patients or as a function of time. The objective of this study was to identify prognostic factors and to estimate individual and time-dependent LRR risk rates.

Methods: Prognostic factors for LRR were identified by a scoping literature review, expert consultation, and stepwise multivariate regression analysis based on 5 years of data from women diagnosed with breast cancer in the Netherlands in 2005 or 2006 ( $n=17$ 762). Inter-patient variability was elucidated by examples of 5-year risk profiles of average-, medium-, and high-risk patients, whereby 6-month interval risks were derived from regression estimates.

Results: Eight prognostic factors were identified: age, tumour size, multifocality, gradation, adjuvant chemo-, adjuvant radiation-, hormonal therapy, and triple-negative receptor status. Risk profiles of the low-, average-, and high-risk example patients showed non-uniform distribution of recurrence risks (2.9, 7.6, and 9.2\%, respectively, over a 5-year period).

Conclusion: Individual risk profiles differ substantially in subgroups of patients defined by prognostic factors for recurrence and over time as defined in 6-month time intervals. To tailor follow-up schedules and to optimise allocation of scarce resources, risk factors, frequency, and duration of follow-up should be taken into account.

With over 1300000 annual cases worldwide (Cardoso et al, 2012), breast cancer accounts for the largest part of the total incidence of female cancer cases every year. The number of new invasive breast cancer cases in the Netherlands is currently $>13000$ per year (Comprehensive Cancer Centers, the Netherlands, 2011), which is $>28 \%$ of all the cancer cases in females. The prevalence of women with breast cancer is rising due to increased survival, caused by earlier detection and treatment and improved outcomes of treatment. However, this means more patients require follow-up care after primary curative treatment, which results in an increasing burden on the health system and hospital resources. The objectives of primary follow-up, according to the European guidelines, are to evaluate late treatment effects, proper wound healing, to screen for psycho-social support, and to detect possible locoregional recurrences (LRRs) (Rojas et al, 2000; Kimman et al, 2007; Aebi et al, 2011; NABON, 2012). In addition to primary follow-up, most patients are offered a minimum of 5 years of annual follow-up, in line with the European guidelines. However, current guidelines typically do not account for individual differences in LRR risks after primary treatment, preventing a 
differentiation in the type of follow-up care. Also, the recommended follow-up in these guidelines is not dependent on recurrence risks over time even though it is known that the recurrence risks are relatively higher in the second and third year after primary curative treatment (Komoike et al, 2006). In addition, the specific form of follow-up care (physical examination and mammography or MRI) can greatly influence the recurrence detection probability (Kolb et al, 2002; Kriege et al, 2004; Montgomery et al, 2007).

A tailored follow-up is a possible approach to increase the efficient use of hospital resources, decrease anxiety, and unnecessary hospital visits for patients during follow-up. With a tailored follow-up, it is expected that equal clinical outcome can be achieved at lower cost by customising the frequency and duration of the follow-up by means of individual LRR risk profiles. When developing tailored follow-up, the risk of distant metastasis should not be included in the profile, because detection is not the primary aim of routine follow-up and early treatment initiation has not been proven to prolong survival at this point (Palli et al, 1999; National Institute for Health and Clinical Excellence, 2002). Previous studies have shown that tailored follow-up appear to be as effective as the more intensive programmes (GIVIO Investigators 1994; Collins et al, 2004; Grunfeld, 2005; Rojas et al, 2000; Kimman et al, 2007). Several studies compared different follow-up programmes and found the less resource intensive programmes to be cost-effective. However, they did not take into account individual recurrence risks (Kimman et al, 2011).

Although the 2007 national guideline of the Netherlands already states that follow-up should be individualised according to an individual patient's LRR (Health Council of the Netherlands, 2007), no clear recommendations are provided to compose and implement an individualised scheme. To obtain tailored schemes, it is important to determine the recurrence risk for the individual patient based on estimations of risk. This, in turn, is based on prognostic factors and risk over time once primary curative treatment has been completed. Estimates of recurrence risks based on prognostic factors are reported in the literature (Campbell et al, 2010; Werkhoven et al, 2011); however, these predict a single risk for a total period of 5 or 10 years. Although there are several studies that report on the recurrence risk based on the primary treatment, there is less information on the specific markers and patient-related factors that are prognostic for a local recurrence.

The objective of this study was to identify prognostic factors and to estimate individual and time-dependent LRR risk rates after primary treatment in 6-month time intervals during a 5-year follow-up period. The individual differences, expressed as LRR risks, and the consequence on health gain and resource use, should provide the rationale to tailor follow-up schemes per patient.

\section{MATERIALS AND METHODS}

Prognostic factors for breast cancer LRR were identified using a three-step approach, including a scoping literature review, expert consultation, and regression modelling. Final quantification of the prognostic value of the identified factors was performed with stepwise multivariate regression analysis.

Scoping literature review. The first pre-selection of prognostic factors was based on a scoping literature review (Rumrill et al, 2010). Following the six-stage methodological framework, as developed by Levac et al (2010), factors that were described in literature as influencing the risk of LRR were included in the selection. The first three stages included the identification of the research question, relevant studies, and defining search terms systematically. The data were charted (stage four) so as to extract relevant results and to summarise the information of each study, per prognostic factor (stage five). Field-experts (stage six) were consulted in order to support and correct the identification of prognostic factors.

Experts. The selection of the prognostic factors from the scoping review was presented to the field-experts $(n=8)$. By means of a questionnaire, the prognostic factors were ranked systematically in the order of importance in predicting recurrence risk. Moreover, the questionnaire enabled the identification of potentially missing factors. The consulted experts were breast radiologists, medical oncologists, and breast cancer surgeons working in two large teaching hospitals, that is, Medisch Spectrum Twente and the Deventer Hospital. The experts were asked to rank the pre-selected factors on a five-point Likert scale, whereby the lower and upper limits represented 'not relevant' and 'essential', respectively. If $>50 \%$ of the experts ranked a prognostic factor as important or essential (equal to 4 or 5 on the survey scale), it was included in the selection. If, at least, over two-thirds of the experts ranked a prognostic factor with 4 or 5 , it was included in the selection, indicating a strong prognostic factor.

Cancer registry data. Patient data were obtained from the Netherlands Cancer Registry (NCR). These data were collected by specially trained registrars, using the hospital medical records. All surgically primary curatively treated invasive breast cancer cases in the Netherlands, diagnosed in 2005-2006 $(n=17762)$ were included. Follow-up data were completed for the 5 years after diagnosis for each patient.

Univariate analysis, using Stata 12.0 (StataCorp LP, College Station, TX, USA), was performed on the prognostic factors, selected by the experts, to determine whether they had a significant prognostic value for LRR. An alpha value of $\leqslant 0.05$ was used as a selection criterion. Factors that did not contribute significantly to the risk of LRR were excluded. A multivariate model was constructed using all univariate-selected prognostic markers. The multivariate model allowed exclusion of non-significant factors and other possible sources of bias. This resulted in the final selection of LRR prognostic factors.

Stepwise regression for variable selection. The selected prognostic factors were also combined in a multivariate analysis to determine odds ratios (ORs) and to quantify the contribution of LRR risk to the total 5-year follow-up period. The same analysis was performed to quantify the contribution of individual factors to each consecutive 6-month time interval during the 5-year period. This time interval corresponds to the follow-up intervals described in multiple guidelines (Aebi et al, 2011; NABON, 2012).

Patient heterogeneity. To demonstrate differences in LRR risk profiles, three example patient types representing a relative low, average, and high LRR risk were defined and used for LRR estimation. Table 1 presents the example patient types based on the selected prognostic factors.

\section{RESULTS}

The results of the scoping literature review, the expert consultations, and the statistical methods used to select the prognostic factors are presented in Table 2. The last column presents the eight prognostic factors that were finally included in the multivariate model construct for predicting a LRR.

The scoping literature review resulted in a selection of 16 possible prognostic factors. The Supplementary Table SII contains a reference list for each of the factors in the selection, and a summary of the description of each prognostic factor. The experts agreed upon 14 factors, which were subsequently tested for 
Table 1. Characteristics of example patients

\begin{tabular}{|l|c|c|c|}
\hline Prognostic factor & $\begin{array}{c}\text { Risk- profile I } \\
(\boldsymbol{n}=103)\end{array}$ & $\begin{array}{c}\text { Risk- profile II } \\
(\boldsymbol{n}=131)\end{array}$ & $\begin{array}{c}\text { Risk- profile III } \\
(\boldsymbol{n}=113)\end{array}$ \\
\hline Age & $\geqslant 50$ & $\geqslant 50$ & $<50$ \\
Triple negative & No & No & No \\
Tumour size & $<2 \mathrm{~cm}$ & $2-5 \mathrm{~cm}$ & $2-5 \mathrm{~cm}$ \\
Chemo therapy ${ }^{\mathrm{a}}$ & Yes & Yes & Yes \\
Radiation therapy & Yes & No & No \\
Gradation & Low & Medium & High \\
Hormonal therapy & Yes & No & No \\
Multifocality & Unifocal & Unifocal & Unifocal \\
\hline \multicolumn{4}{|l}{} \\
aAfter surgery in adjuvant treatment setting.
\end{tabular}

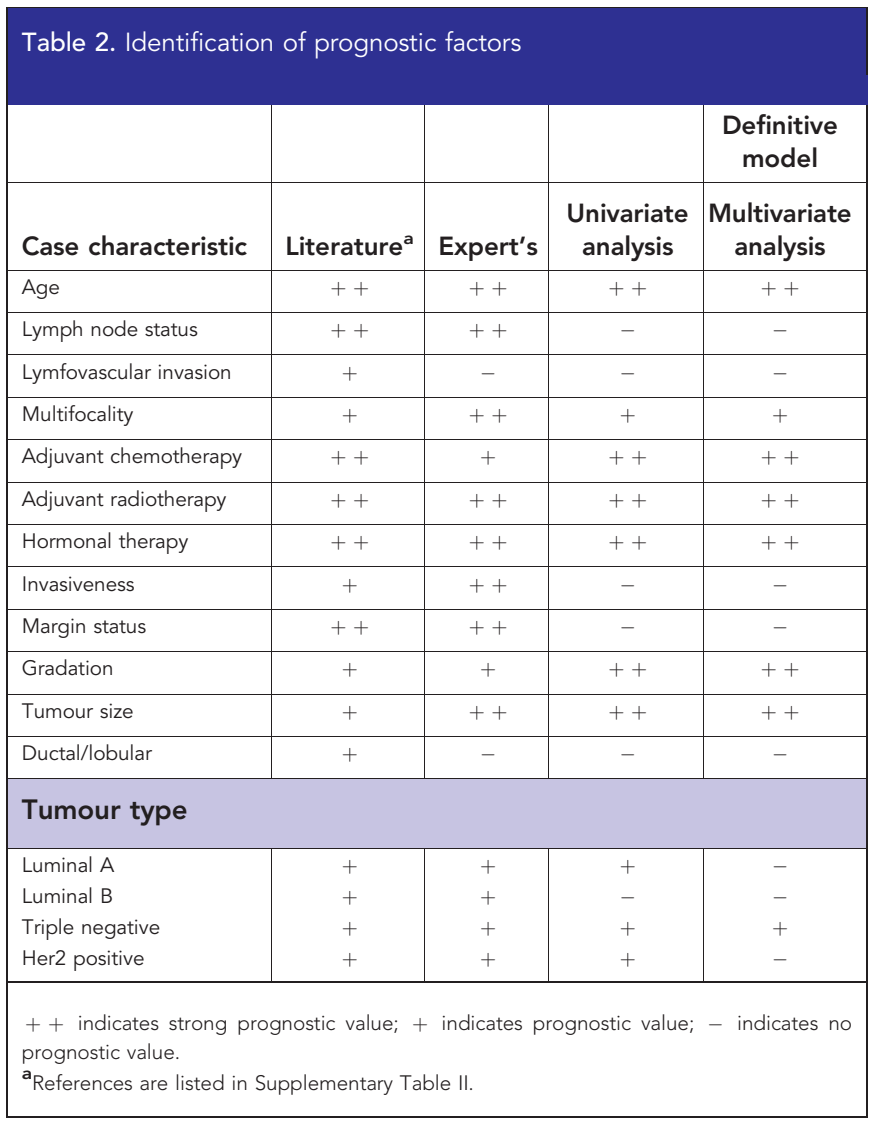

significance of prognostic value. The final univariate selection resulted in a set of 11 factors. Step-wise selection of these 11 factors led to the selection of the 8 prognostic factors in the multivariate model to predict the risk of a LRR (Table 2).

The risk of a LRR is presented by the ORs (Table 3). The ORs present the overall 5-year risk for each individual factor as well as the complete multivariate model. Table 3 shows that age $>50$ years and adjuvant therapy decrease the risk of LRR. Multifocality, tumour grade, tumour size and triple-negative receptor status led to an increase in LRR risk. Moreover, LRR risk appeared to be time dependent (Table 3). The prognostic values per 6-month time interval are presented in Supplementary Table SI.

The 5-year LRR risk estimates for the study population (Figure 1) show that the highest risk of LRR is between 2 and 3 years after primary treatment. The highest LRR risk over a 5-year period is $1.2 \%$ at 2.5 years after primary treatment. In addition,
Table 3. Results of multivariate analysis and population characteristics

\begin{tabular}{|l|c|c|c|c|}
\hline Case characteristic & $\begin{array}{c}\text { No. of } \\
\text { patients }\end{array}$ & OR & P-value & $\mathbf{9 5 \% ~ C l}$ \\
\hline Age & $\begin{array}{r}4566 \\
13196\end{array}$ & $\begin{array}{c}1 \\
0.63\end{array}$ & $<0.001$ & $0.51-0.78$ \\
\hline $\begin{array}{l}<50 \text { years } \\
\geqslant 50 \text { years }\end{array}$ & $\begin{array}{r}14496 \\
2683\end{array}$ & $\begin{array}{l}1 \\
1.3\end{array}$ & 0.024 & $1.04-1.63$ \\
\hline Multifocality & $\begin{array}{l}\text { No } \\
\text { Yes }\end{array}$
\end{tabular}

Adjuvant chemotherapy

\begin{tabular}{|l|r|l|l|l|}
\hline No & 11302 & 1 & & \\
Yes & 6459 & 0.55 & $<0.001$ & $0.44-0.70$ \\
\hline
\end{tabular}

Adjuvant radiotherapy

\begin{tabular}{|l|r|l|l|l|}
\hline $\begin{array}{l}\text { No } \\
\text { Yes }\end{array}$ & $\begin{array}{r}6104 \\
11657\end{array}$ & $\begin{array}{l}1 \\
0.68\end{array}$ & $<0.001$ & $0.57-0.82$ \\
\hline \multicolumn{5}{|l|}{ Hormonal therapy } \\
\hline $\begin{array}{l}\text { No } \\
\text { Yes }\end{array}$ & $\begin{aligned} \\
770054\end{aligned}$ & $\begin{array}{l}1 \\
0.54\end{array}$ & $<0.001$ & $0.43-0.69$ \\
\hline
\end{tabular}

\begin{tabular}{|l|l|l|l|l|}
\hline Gradation \\
\hline Low & 3748 & 1 & & \\
Medium & 7450 & 1.83 & $<0.001$ & $1.37-2.43$ \\
High & 5472 & 2.98 & $<0.001$ & $2.17-4.10$ \\
\hline
\end{tabular}

Tumour size

\begin{tabular}{|c|r|c|c|c|}
\hline$<2 \mathrm{~cm}$ & 11021 & 1 & & \\
$2-5 \mathrm{~cm}$ & 6100 & 1.51 & $<0.001$ & $1.23-1.84$ \\
$>5 \mathrm{~cm}$ & 516 & 1.63 & 0.05 & $1.00-2.67$ \\
\hline
\end{tabular}

Triple negative

\begin{tabular}{|l|r|r|r|l|}
\hline No & 10905 & 1 & & \\
Yes & 1888 & 1.56 & 0.012 & $1.1-2.21$ \\
\hline B-O-constant & & -2.8 & & \\
\hline
\end{tabular}

Abbreviations: $\mathrm{Cl}=$ confidence interval; $\mathrm{OR}=$ odds ratio.

three hypothetical patients are represented in Figure 2 and Table 1, respectively. The three profiles demonstrate a cumulative risk of 2.9, 7.6, and 9.2\%, respectively, for LRR over a 5-year period. By using the underlying betas, it is possible to calculate LRR risks for each value of the selected prognostic factors representing any patient type.

\section{DISCUSSION}

This study systematically identified the eight most important prognostic factors predicting the risk of LRR: age, tumour size, multifocality, gradation, adjuvant chemotherapy, adjuvant radiation therapy, hormonal therapy, and triple-negative status. This study revealed that LRR risk is largely dependent on the follow-up time after primary treatment. Heterogeneity due to patient-related factors, tumour and treatment characteristics, and time after primary treatment were examined and confirmed by means of three hypothetical patient profiles.

Although for certain types of patients the LRR risk is higher after breast conserving surgery (BCS; Sangen et al, 2011) and 
Five-year risk distribution of study population

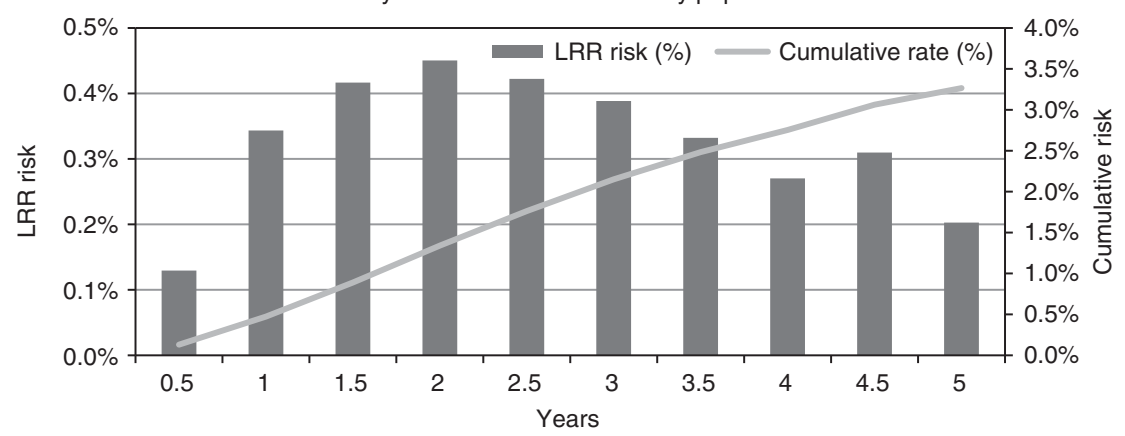

Figure 1. Five-year risk spread of study population.

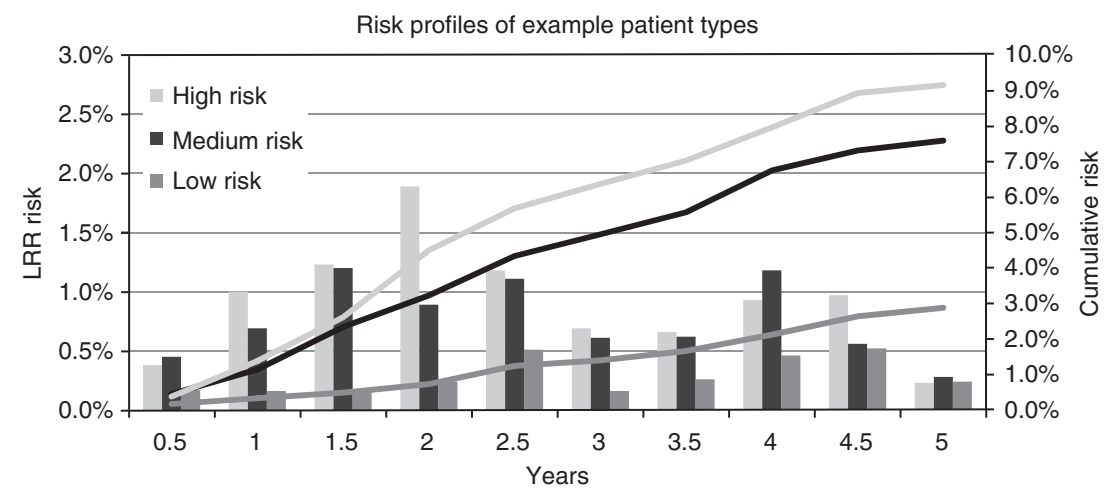

Figure 2. LRR profile of example patients.

reports of the effect of primary surgery on overall survival and local control are ambiguous (van Tienhoven et al, 1999; van der Hage et al, 2003; Bantema-Joppe et al, 2011; Litière et al, 2012; Zumsteg et al, 2013), the type of primary surgery was not selected as a variable representing the risk for LRR. This decision was based on both the scoping literature review and the consultation of experts as the experts' survey explicitly offered the opportunity to select primary surgery as a variable. Yet, as type of primary surgery was available in the data set, it was possible to check whether leaving out the type of surgery was appropriate. To do so, patients were divided in two groups based on the type of primary surgery, either BCS or mastectomy (MT). In general, patients with MT were older and had larger tumours with higher grades. Including the type of primary surgery in univariate and multivariate analysis as a separate variable resulted in no significant changes in outcomes (univariate: OR 1.31 95\% confidence interval (CI) ( $-0.003-0.056)$, multivariate: OR $1.0195 \%$ CI $(-0.040-0.067))$. The OR of the univariate analysis suggests a predictive value of primary surgery type; however, as the multivariate OR shows, this is due to other variables used for type of surgery indication. This confirms the decision not to include the type of primary surgery, and the data were analysed irrespective of type of primary surgery.

The risk of LRR over a 5-year period fluctuated over time, with the highest risk $(1.2 \%)$ at 2.5 years after primary treatment. This is in agreement with Komoike et al (2006), who concluded that the highest risk of LRR was found between 2 and 3 years after primary treatment, implicating that there should be an increased focus on planning follow-up in these intervals. Fluctuation of risk over time and patient heterogeneity are two important arguments for tailoring follow-up.

Improved LRR risk predictions, as highlighted in this study, are highly relevant for the allocation of resources and to decrease patient anxiety, as unnecessary follow-up visits can be reduced.
In order to tailor follow-up for breast cancer patients, individualised risk profiles are the first step. In line with the implications for resource use, individual risk profiling can increase adherence to returning for primary care or a screening programme. Moreover, patients with a relative low risk of LRR could be assigned to different, less costly, types of follow-up, for example, an e-health system of telephone consultations (Kimman et al, 2011).

One of the strengths of this study is the combination of scoping literature review, expert consultation, and data analysis, as this improves the single-focus methods used to assess the risk of LRR up to now (Komoike et al, 2006; Sanghani et al, 2007; Abi-Raad et al, 2011). A combination of prognostic factors selected by the three-step approach is described in this study, for the first time. This approach includes all the essential factors selected in the study, giving a plausible profile of the patient in order to calculate the risk of LRR.

This study determined the time-dependent occurrence of a LRR risk after primary treatment per 6-month time intervals for a total of 5 years. The rationale for the 6-month intervals is consistent with the recommended follow-up intervals (Cardoso et al, 2012). As this study produced a continuous description of individual risk profiles, it differs from other research groups' calculation methods. These methods only provide a single-point estimate for a period of 5 or 10 years (Sanghani et al, 2010). The continuous registration enables effective calculations of single changes in follow-up strategies.

All patients who had received primary curative treatment between 2005 and 2006 were included in the study population. This study used a large, homogeneous, population-based data set from the NCR, which was registered by specially trained registrars, whereas other studies used, for example, questionnaires to obtain patient data (Komoike et al, 2006). As the selected prognostic factors are already registered systematically in clinical 
practice, the data can be easily used to determine LRR risks in future cases.

Although the total number of included patients was very large, 17762 , some limitations in estimating all the LRR risks accurately for every patient type were encountered. This was due to the low recurrence rates of, for example, patients with a triple-negative status (only $11 \%$ of the population). The $95 \%$ CI of this coefficient was therefore wide (1.1-2.2) in comparison to the CIs of the other factors. To improve the accuracy of the calculated contribution to the LRR risks, the number of patients included in future studies should be increased. All of the factors have a CI that was conclusive regarding their contribution to the LRR risk: they either increase or decrease the risk. Moreover, future extensions of the database should be used to validate the regression model.

\section{CONCLUSION}

Risk profiles, which improve risk predictions, differ per individual patient due to the identified eight prognostic factors for recurrence and over 6-month time intervals. As illustrated by the risk profiles of three patient type examples, the study demonstrates the quantification of LRR risks. When tailoring follow-up, risk factors, frequency, and duration of follow-up should be taken into account, in order to optimise allocation of resources and capacity planning. Our LRR risk profiling offers the first step towards the tailored follow-up, whereby individualised follow-up strategies, as part of the trend in personalised medicine, are inevitable strategies for the future of breast cancer care.

\section{ACKNOWLEDGEMENTS}

We thank the employees of the Netherlands Cancer Registry (NCR) for providing the data of the cancer cases in the Netherlands. We would also like to thank ABG Kwast (IKNL) for editing and selecting the database for this study. In addition, we appreciate the response of the expert panel; all the involved fieldexperts are thanked for their contribution.

\section{CONFLICT OF INTEREST}

The authors declare no conflict of interest.

\section{REFERENCES}

Abi-Raad R., Boutrus R, Wang R, Niemierko A, Macdonald S, Smith B, Taghian G (2011) Patterns and risk factors of locoregional recurrence in T1-T2 node negative breast cancer patients treated with mastectomy: implications for postmastectomy radiotherapy. Int J Radiat Oncol Biol Phys 81(3): e151-e157.

Aebi S, Davidson T, Gruber G, Castoglione M (2011) Primary breast cancer: ESMO Clinical Practice Guidelines for diagnosis, treatment and follow-up. Ann Oncol 22(suppl 6): vi12-vi24.

Bantema-Joppe EJ, de Munck L, Visser O, Willemse P, Langendijk J, Siesling S, Maduro J (2011) Early-stage young breast cancer patients: impact of local treatment on survival. Int J Radiat Oncol Biol Phys 81(4): e553-e559.

Campbell H, Gray A, Harris A, Briggs A, Taylor M (2010) Estimation and external validation of a new prognostic model for predicting recurrencefree survival for early breast cancer patients in the UK. Br J Cancer 103(6): 776-786.

Cardoso F, Harbeck N, Fallowfield L, Kyriakides S, Senkus E (2012) Locally recurrent or metastatic breast cancer: ESMO Clinical Practice Guidelines for diagnosis, treatment and follow-up. Ann Oncol 23(suppl 7): viil1-vii19.
Collins R, Bekker HL, Dodwell DJ (2004) Follow-up care of patients treated for breast cancer: a structured review. Cancer Treat Rev 30(1): $19-35$.

Comprehensive Cancer Centers, the Netherlands (2011) Dataset Breast Cancer from http://www.cijfersoverkanker.nl/selecties/Dataset_1/ img4f3ba09dec237. Retrieved on 9 December 2012.

GIVIO Investigators (1994) Impact of follow-up testing on survival and health-related quality of live in breast cancer patients. JAMA 271: 20.

Grunfeld E (2005) Clinical practice guidelines for the care and treatment of breast cancer: follow-up after treatment for breast cancer (summary of the 2005 update). CMAJ 172(10): 1319-1320.

Health Council of the Netherlands (2007) Follow-up in oncology: 154.

Kimman ML, Voogd AC, Dirksen CD, Falger P, Hupperets P, Keymeulen K, Hebly M, Dehing C, Lambin P, Boersma LJ (2007) Follow-up after curative treatment for breast cancer: why do we still adhere to frequent outpatient clinic visits? Eur J Cancer 43(4): 647-653.

Kimman ML, Dirksen CD, Voogd AC, Falger P, Gijsen BCM, Thuring M, Lenssen A, van der Ent F, Verkeyn J, Haekens C, Hupperets P, Nuytinck JKS, van Riet Y, Brenninkmeijer SJ, Scheijmans LJEE, Kessels A, Lambin P, Boersma LJ (2011) Economic evaluation of four follow-up strategies after curative treatment for breast cancer: results of an RCT. Eur J Cancer 47(8): 1175-1185.

Kolb TM, Lichy J, Newhouse JH (2002) Comparison of the performance of screening mammography, physical examination, and breast US and evaluation of factors that influence them: an analysis of 27,825 patient evaluations. Radiology 225(1): 165-175.

Komoike Y, Akiyama F, Ilno Y, Ikeda T, Tanaka S, Ohsumi S, Kusama M, Sano M, Shin E, Seumasu K, Sonoo H, Taguchi T, Nishi T, Nishmura R, Haga S, Mise K, Kinoshita T, Murakami S, Yoshimoto M, Tsukama H, Inaij H (2006) Ipsilateral breast tumor recurrence (IBTR) after breast-conserving treatment for early breast cancer. Cancer 106(1): $35-41$.

Kriege M, Brekelmans CTM, Boetes C, Besnard PE, Zonderland HM, Obdeijn IM, Manoliu RA, Kok T, Peterse H, Linthorst MMA, Muller SH, Meijer S, Oosterwijk JC, Beex LVAM, Tollenaar RAEM, de Koning HJ, Rutgers EJT, Klijn JGM (2004) Efficacy of MRI and mammography for breast-cancer screening in women with a familial or genetic predisposition. $N$ Engl J Med 351(5): 427-437.

Levac D, Colquhoun H, O’Brien KK (2010) Scoping studies: advancing the methodology. Implement Sci 5(1): 69.

Litière S, Werutsky G, Fentiman IS, Rutgers E, Christiaens MR, van Limbergen E, Baaijens MH, Bogaerts J, Bartelink H (2012) Breast conserving therapy versus mastectomy for stage I-II breast cancer: 20 year follow-up of the EORTC 10801 phase 3 randomised trial. Lancet Oncol 13(4): 412-419.

Montgomery DA, Krupa K, Jack WJL, Kerr GR, Kunkler IH, Thomas J, Dixon JM (2007) Changing pattern of the detection of locoregional relapse in breast cancer: the Edinburgh experience. Br J Cancer 96(12): 1802-1807.

NABON (2012) Guideline Breast Cancer (Richtlijn Mammacarcinoom) pg.199.

National Institute for Health and Clinical Excellence (2002) Guidance on cancer service: improved outcomes in breast cancer care. Manual update, from http://guidance.nice.org.uk/CSGBC/Guidance/pdf/English.

Palli D, Russo A, Saieva RAC, Ciatto S, Rosselli Del Turco M, Distante V, Pacini P (1999) Intensive vs clinical follow-up after treatment of primary breast cancer: 10-year update of a randomized trial. JAMA 281(17): 1586-1586.

Rojas MPMP, Telaro E, Moschetti I, Coe L, Fossati R, Liberati A, Rosselli MDT (2000) Follow-up strategies for women treated for early breast cancer. Cochrane Database Syst Rev (4): Art. No: CD001768. doi: 10.1002/14651858.CD001768.pub2.

Rumrill PD, Fitzgerald SM, Merchant WR (2010) Using scoping literature reviews as a means of understanding and interpreting existing literature. Work 35(3): 399-404.

Sangen MC, Wiel FM, Poortmans PM, Tjan-Heijnen VC, Nieuwenhuijzen G, Roumen RM, Ernst M, Tutein Nothenius-Puylaert M, Voogd AC (2011) Are breast conservation and mastectomy equally effective in the treatment of young women with early breast cancer? Long-term results of a population-based cohort of 1,451 patients aged $\leq 40$ years. Breast Cancer Res Treat 127(1): 207-215.

Sanghani M, Balk E, Cady B, Wazer D (2007) Predicting the risk of local recurrence in patients with breast cancer. Am J Clin Oncol 30(5): 473-480. 
Sanghani M, Truong PT, Abi Raad R, Niemierko A, Lesperance M, Olivotto IA, Wazer DE, Taghain AG (2010) Validation of a web-based predictive nomogram for ipsilateral breast tumor recurrence after breast conserving therapy. J Clin Oncol 28(5): 718-722.

van der Hage J, Putter H, Bonnema J, Bartelink H, Therasse P, van de Velde CJH (2003) Impact of locoregional treatment on the early-stage breast cancer patients: a retrospective analysis. Eur J Cancer 39(15): 2192-2199.

van Tienhoven G, Voogd AC, Peterse JL, Nielsen M, Andersen K, Mignolet F, Sylvester R, Fentiman IS, van der Schueren E, van Zijl K, Blichert-Toft M, Bartelink H, van Dongen JA (1999) Prognosis after treatment for locoregional recurrence after mastectomy or breast conserving therapy in two randomised trials (EORTC 10801 and DBCG-82TM). Eur J Cancer 35(1): $32-38$.
Werkhoven E, Hart G, Tinteren H, Elkhuizen P, Collette L, Poortmans P, Bartelink H (2011) Nomogram to predict ipsilateral breast relapse based on pathology review from the EORTC 22881-10882 boost versus no boost trial. Radiother Oncol 100(1): 101-107.

Zumsteg Z, Morrow M, Arnols B, Zheng J, Zhang Z, Robsons M, Traina T, McCornmick B, Powell S, Ho A (2013) Breast-conserving therapy achieves locoregional outcomes comparable to mastectomy in women with T1-2N0 triple-negative breast cancer. Ann Surg Oncol; e-pub ahead of print 19 May 2013; doi:10.1245/s10434-013-3011-9.

This work is published under the standard license to publish agreement. After 12 months the work will become freely available and the license terms will switch to a Creative Commons AttributionNonCommercial-Share Alike 3.0 Unported License.

Supplementary Information accompanies this paper on British Journal of Cancer website (http://www.nature.com/bjc) 